\title{
REHABILITATION AFTER TRAUMATIC AMPUTATION OF THE LOWER LIMB ${ }^{\dagger}$
}

\section{MISS M. HUMPHREY*}

Traumatiese ampulasies, as gevolg van landmynontploffings word genoem. Drie fases van post-operaliewe behandeling word bespreek, naamlik die vroee fase in die saal, die intermediêre fase in die gimnasium en die finale stadium wanneer' $n$ prostese gepas is en loopgang rehabilitasie plaasvind.

It has been said that we are rapidly becoming a race of one-legged people - probably an exaggeration nevertheless a sign of the times.

People have been, to date, more familiar with amputations owing to road, industrial and agricultural accidents. However, of all the causes of traumatic amputafons war injuries are the most devastating.

Anti-personnel mines are designed to maim rather than to kill, while land mines and high velocity, missiles have a "shattering" effect - in more senses than one on soldiers and civilians alike.

Blast injuries are a new dimension in traumatic amputations and, together with those other injuries mentioned previously, add to the formidable total of limbs lost during a year. This number, naturally, covers men and women from all walks of life and includes all races. However, because of numerical superiority, the grèatest incidence of amputees occurs among the African population as a large number are victims of terrorism.

After all the necessary life-saving measures have been performed, the initial treatment is "wound toilet". In blast injuries this is essential as shrapnel from the mine, vehicle parts, stones and clothing, may be embedded in the wound. In such cases the wound is left open until all danger of sepsis is past. This may take a considerable time. Secondary closure is then performed and a soft dressing applied. This is held in place by a pressure bandage to give maximum support to the wound and prevent oedema.

The most satisfactory stumps are those which are end bearing and where muscle fixation is achieved by myofascial closure over the bone end or by myodesis, attaching the muscles directly to the tibia or femur by way - af sutures through drill holes in the bone. This allows ae severed muscles to be exercised thereby retaining muscle bulk and promoting good circulation which keeps the skin healthy and which in turn prevents ulceration of the stump.

Length is equally important because the longer the stump the greater the leverage and the less effort is required to manipulate the prosthesis.

Rehabilitation starts immediately after surgery. Postoperative physical treatment is divided into three phases:

The early phase in the ward.

The intermediate phase in the gym.

The final stage when the prosthesis is fitted.

\section{Early Phase}

Initially a fracture board should be placediunder the mattress allowing for good positioning of the stump; where possible the patient is nursed on his back as side

* Physiotherapist, Workmen's Rehabilitation Centre, Bulawayo.

$\dagger$ Paper presented at a Congress on Trauma in Durban, May 1977. lying encourages hip flexion. Flexion contraction of the hip joint especially in above-knee amputee is inevitable unless the therapist is on the lookout and ready to counter any tendency the patient may have which will encourage this. No pillows are allowed under the stump for the same reason. However if you can prevent a patient sneaking a pillow under the stump at some time during the night or day you are a lot cleverer than $I$ $\mathrm{am}$ !

As soon as the patient is well enough he should be asked if he can still feel his leg. Whatever his reply it is important to explain that phantom pains might occur and that the limb will gradually appear to shrink and get shorter until it eventually disappears.

This explanation is particularly important when treating African patients as they are afraid to mention it in case it is some kind of witchcraft.

From the first to the fifth day breathing exercises and general bed exercises are encouraged.

On the third day, if other injuries permit, prone lying for 15 minutes, three times per day, is introduced.

Drains or suction may be removed from the wound at this time and if the patient is allowed up, encourage standing and balancing with support. Crutch walking is started the fourth day. Whenever possible use elbow crutches, not axillary crutches or a wheeled walker. Specific stump exercises in lying or standing are started. These include adduction and extension exercises in above-knee amputees and in below-knee amputees, exercises to strengthen the quadriceps. Stitches are removed on the tenth day and if the incision is well healed, firm stump bandaging should start.

It is important to use a bandage of the correct width. A $150 \mathrm{~mm}$ woven cotton and elastic bandage should be used for an above-knee stump and a $100 \mathrm{~mm}$ bandage for a below-knee stump. When applying the bandage ensure that it is applied in a spiral. In a below-knee amputee start the bandage above the knee and include the joint. This prevents occlusion of the vessels behind the knee joint and strangling of the stump. It also ensures a better shape for prosthetic fitting.

In the above-knee amputee see that the bandage goes right up into the groin to avoid getting a flesh roll forming there as this makes limb fitting difficult. Coning is essential for a prosthesis to be fitted to a stump. For it to function adequately, the stump must be fully shrunk and shaped before measurements for a limb are taken.

At first the patient will only tolerate pressure for a short period so that the bandage will have to be reapplied frequently. However, tolerance soon builds up until the bandage need only be applied four times per day. The patient should be taught how to apply his own bandage. The bandage should be worn at night and even when he has received his prosthesis this practice should continue. He should also be told at this stage that if in the future he has to discard his prosthesis for any length of time, e.g. if it is being repaired, he must ensure that his stump is bandaged during the interval. Failure to do so may result in swelling of the stump and discomfort when he puts on his prothesis again.

\section{The Intermediate Phase}

This includes a full programme of general exercises in the gym and pool to which are added specific stump 
exercises. These progress from free exercises to resisted exercises using springs or weights. Balance exercises are of paramount importance and should be practised until the patient is almost as mobile on one leg as he was on two.

This point will be appreciated should he stumble when he starts walking on his pylon. If he has been well taught he will usually be able to recover his equilibrium without falling. It is both physically and psychologically important to get the patient walking as early as possible and the use of a temporary pylon cannot be over stressed. He is gradually encouraged to dispense with crutches or a cane. This is very necessary for a man whose job may entail carrying loads or equipment once he returns to work.

At this stage the exercise programme is extended to the occupaitonal therapy department and an assessment is made as to whether or not the patient will be able to return to his former employment. If this is not possible arrangements should be set in motion for vocational training so that there is no hiatu's in his recovery programme.

The aforementioned programme will have to be modified to accommodate associated injuries, the most common being fractures of the other limb or pelvis and in blast injuries fracture of the skull or spine.

After 6-8 weeks the stump should be ready for measuring for a prosthesis.

To digress, apart from the injuries which are obvious at the time of the accident, in blast injuries which are caused by mines or bombs the physiotherapist who has probably the closest and lengthiest association with the patient should be on the alert for complications which may only be manifested at a later date. Deafness and eye symptoms are the most common, and in the below knee amputation some form of internal derangement may be present which shows up only when the patient starts walking.

\section{Final Stage}

The Fitting of a Prosthesis: When discussing the type of prosthesis which is to be ordered for the patient the following points should be taken into consideration:-

1. Of prime importance is the distance he lives from the nearest Orthopaedic Centre or limb factory. Many of the smaller countries have only one or two limb fitting centres serving the whole area. Qualified prosthetists in most countries are extremely scarce. Those that are available are usually grossly overworked and have a tremendous backlog so that even the simplest repair may mean that the man is derived of the use of his limb for several weeks.

2. The next point to be considered is the nature of his work, if he has a sedentary job, or whether he is an industrial or farm labourer which could entail a lot of walking.

3. Thirdly, whether the patient lives in a town or tribal village. A fully articulated leg may be satisfactory in an urban area, but in a rural area where the recipient has to walk long distances in all weathers, S.A.C.H. feet and ankle joints do not take kindly to constant immersion in water or the rigours of walking in a muddy field in addition to which the nearest main road and bus or train route may be many miles from his home. In these circumstances a peg is more practical and will give much better service.
In my opinion the fitting of a modular prosthesis
would appear to be the best solution to some of would appear to be the best solution to some of these
problems. A modular prosthesis is one that can assembled to a high degree from prefabricated be and can be adjusted on the amputee very rapidly bring it to optimum function. It would also be to more satisfactory and less costly to fit the patient much a temporary limb, which can be assembled by with physiotherapist, as soon as possible and to send the home as soon as he is walking well. He should him instructed to report to the nearest Physiotherapy depart. ment or Physiotherapist should the limb need adjustment until such time as he is ready for a definitive prosthesis.

The Winnipeg modular prosthesis was introduced in 1965 and has now become standardised. There is German model which is proving satisfactory and the a is a Japanese variation which is even simpler to assemble and adjust. In the interest of the patient this should be the prosthesis of choice which should be used in the future.

There is one snag. Not many physiotherapists have the knowledge to fit the patient, assemble the prosthesis and do the adjustments. Prosthetics and Orthotics seem to be a blind spot in the scope of our work and 1 feel that this may stem from an apparent lack in initial training. The need for therapist involvement is great. A few of us were fortunate enough to do our training during the last war when a situation similar to the one today, existed and our interest in this field was stimulated. Today we are much more fortunate in that we have the materials to make the do-it-yourself splint comparatively easily and, given the necessary instruction, a great contribution could be made to the existing need to fit a brace or limb promptly.

I do not propose to discuss the various types of lower limb prosthesis. Two categories of patients deserve special mention. The first is the bilateral above-knee amputee with short stumps who poses the question Is he going to be a successful walker or is he going to find the effort too great and become a dispirited wheelchair addict?

It seems the answer is not to be too ambitious when ordering his prosthesis. If you can convince the patient that shorter legs will require less physical effort to walk and that the closer he is to the ground the greater his confidence will be, you will have a happy walker.

Beware of the enthusiast who tries to persuade you and the patient that his psyche will suffer because he is several feet shorter than his fellowmen. If you should submit and order long legs, the result will be that in a very short time you will have a fat miserable squatter on your hands.

In the second category is the man who has had a hemipelvectomy. Although great strides have been made in producing a fairly sound prosthesis some patients will protest that this is too heavy and they prefer to use crutches. Don't be too hard on them as they have a point.

The most successful walkers are those with a wellfitting end-bearing prosthesis. They should present few problems provided they have been given adequate instruction in stump hygiene and management. The least successful are those who have been given limbs where the effort required to manipulate the leg out-weighs its usefulness. 